
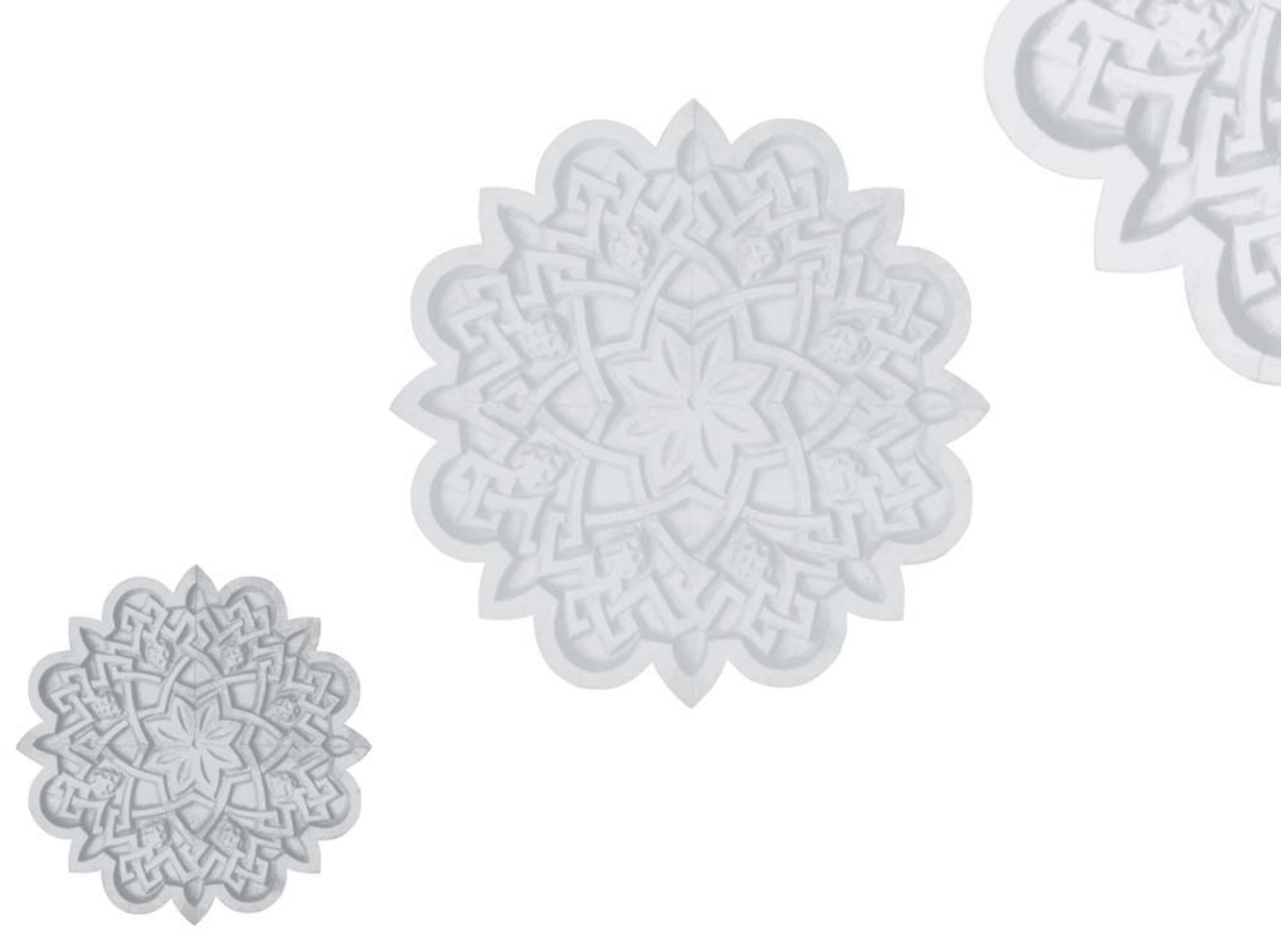


\section{Diálogos entre Clio e Asclépio: Ivolino de Vasconcellos e a Revista Brasileira de História da Medicina*}

\section{Dialogues between Clio and Asclepius: Ivolino de Vasconcellos and the Revista Brasileira de História da Medicina}

Mauro Amoroso

Mestre em história, editor da revista eletrônica Cantareira m.amoroso@globo.com
AMOROSO, Mauro. Diálogos entre Clio e Asclépio: Ivolino de Vasconcellos e a Revista Brasileira de História da Medicina. História, Ciências, Saúde - Manguinhos, Rio de Janeiro, v.14, n.1, p.259-268, jan.-mar. 2007.

O Instituto Brasileiro de História da Medicina foi fundado em 1945 pelo médico Ivolino de Vasconcellos. Como pretendia ter caráter nacional, foi criada também a Federação Nacional de História da Medicina e Ciências Afins. Esse grupo possuía uma concepção humanística de medicina, tendo a história da medicina papel central, por ser instrumento vital para a formação ética e humanista do profissional da área médica através da celebração de seus grandes nomes e realizações. Desse modo, foi lançada, em 1949, a Revista Brasileira de História da Medicina, publicação que estimulou a produtividade e a realização de eventos científico-acadêmicos em história da medicina e registrou as atividades da Federação, bem como sua produção científica.

PALAVRAS-CHAVE: Revista Brasileira de História da Medicina; Instituto Brasileiro de História da Medicina; Federação Nacional de História da Medicina e Ciências Afins; Ivolino de Vasconcellos.

AMOROSO, Mauro. Dialogues between Clio and Asclepius: Ivolino de Vasconcellos and the Revista Brasileira de História da Medicina.

História, Ciências, Saúde - Manguinhos, Rio de Janeiro, v.14, n.1, p.259-268, Jan.-Mar. 2007.

The Brazilian Institute for the History of Medicine was founded on 1945 by the physician Ivolino de Vasconcellos. Because the movement intended to be of national scope, the Federação Nacional de História da Medicina e Ciências Afins was also created (National Federation for the History of Medicine and Related Sciences). The latter group had a humanistic understanding of medicine, wherein the history of medicine played a central role; since this subject honored great names and achievements in medicine, members of the federation felt it was a prime tool in the ethical and humanistic training of healthcare professionals. Thus was born the Revista Brasileira de História da Medicina, which fostered scientific and academic production and events in the field of history of medicine and also registered the Federation's activities and scientific output.

KEYWORDS: Revista Brasileira de História da Medicina; Brazilian Institute for the History of Medicine; National Federation of the History of Medicine and Related Sciences; Ivolino de Vasconcellos. 
* O presente artigo originou-se de trabalho realizado com o apoio do Conselho Nacional de Desenvolvimento Científico e Tecnológico (CNPq) Brasil. Agradeço, também, aos doutores Waldenir de Bragança e Miguel de Freitas Pereira pela participação fundamental na elaboração deste estudo.

${ }^{1}$ Nos últimos anos da revista nota-se um considerável decréscimo desse tipo de propaganda, talvez em virtude do delicado momento financeiro pelo qual o país passava no início da década de 1960, que deve ter influenciado decisivamente para o seu encerramento. Infelizmente, por falta de fontes, não foi possível a verificação dessa e de outras hipóteses sobre a revista e o IBHM, uma vez que seus exemplares são a única fonte existente para o seu estudo.

\footnotetext{
${ }^{2}$ A BBHC pode ser consultada pelo site http:// www.mast.br.
}

F undado em 30 de novembro de 1945, o Instituto Brasileiro de de Historia da Medicina e Ciências Afins, surge em um periodo caracterizado, no Brasil, por uma história da ciência em fase embrionária, ainda praticada por cientistas interessados em estudar o advento de suas respectivas áreas. Em 1949 o Instituto lançaria a Revista Brasileira de História da Medicina (RBHM), com o objetivo de impulsionar a produção e divulgar o conhecimento na área da história da medicina, além de produzir registros históricos sobre o Instituto e a Federação.

A periodicidade da revista variou ao longo dos anos. Começou como publicação trimestral e assim permaneceu até julho de 1956, quando se tornou mensal, até 1958. Circulou com periodicidade bimestral, com pequenas variações, de 1959 até o ano de 1963, sendo lançada, posteriormente, uma única edição relativa ao biênio 1969-1970. A RBHM era enviada a assinantes e instituições científicas e culturais com as quais mantinha permuta, dependendo sua manutenção financeira das assinaturas e da publicidade de laboratórios farmacêuticos. ${ }^{1}$

O presente artigo objetiva caracterizar e debater a conceituação dehistória da medicina para os membros do Instituto Brasileiro de História da Medicina e da Federação, principalmente Ivolino de Vasconcellos, bem como analisar o caráter e a repercussão desse movimento e de suas realizações, a fim de situá-lo, levantando, também, questões relativas a seu alcance e sua importância para a história da ciência no Brasil. Para tal fim, serão analisadas passagens de seções específicas da Revista Brasileira de História da Medicina e resultados gerais da indexação dos artigos nela contidos e que foram inseridos na Bibliografia Brasileira de História da Ciência (BBHC).

O projeto no qual minha pesquisa se insere, "As ciências e sua história: uma análise bibliográfica", coordenado por Alfredo Tiomno Tolmasquim, visa mapear a história da ciência no Brasil, através, principalmente, do levantamento e da análise de sua produção bibliográfica. Tal levantamento alimenta a $\mathrm{BBHC}^{2}$, que constituirá importante instrumento para divulgação internacional da produção bibliográfica brasileira no campo da história da ciência, uma vez a que faz parte de um projeto de produção de redes supranacionais de informação em história da ciência e tecnologia que visa a constituição de uma base internacional denominada International Bibliographical Database in History of Science, Technology and Medicine, coordenada pela Commission on Bibliography and Documentation, da International Union of History and Philosophy of Science. 


\section{História da ciência no Brasil}

As primeiras produções envolvendo história da ciência no Brasil datam do século XIX. Eram complementares ao trabalho científico e consistiam basicamente em biografias, relatos de instituições e/ou eventos científicos (Tolmasquim, Costa, Lino, 2001). Exemplificando tais produções, temos: Ladislau Neto, Investigações históricas e científicas sobre o Museu Imperial e Nacional (1870), Louis Couty, O ensino superior no Brasil (Gazeta Médica da Bahia, 1884) e A. Goeldi, "Algumas notícias sobre a vida de Alexandre Rodrigues Ferreira" (Revista da Sociedade de Estudos Paraenses, t.1, fasc.3, 1894), entre outros.

No início do século XX, oito anos antes da fundação do Instituto Brasileiro de História da Medicina, fez-se a primeira tentativa de organização institucional da história da ciência no Brasil, com a fundação da Academia Brasileira de História da Ciência (1937). Era formada por cientistas que tinham a pretensão de inserir a história da ciência produzida no Brasil no âmbito internacional, com a ajuda da Academie International d'Histoire des Sciences, à qual tais cientistas eram ligados. Em 1955 é assentado um marco na historiografia da ciência no Brasil, com o lançamento de As ciências no Brasil, coletânea organizada por Fernando de Azevedo com artigos elaborados por cientistas que contam a história de suas respectivas áreas.

Cátedras em história da ciência começaram a surgir em algumas universidades já nos anos 1960. Na década seguinte, a institucionalização da história da ciência no Brasil foi impulsionada pela criação de institutos e centros de pesquisa e ensino. Como mostra A.M. Alfonso-Goldfarb (1994), observa-se nesse processo - sobretudo durante as décadas de 1950 e 1960 - uma tendência interdisciplinar que aproximou a história da ciência das questões teórico-metodológicas pertinentes a outras áreas, como a sociologia, a antropologia e a própria história. Isso contribuiu para a abertura de novos caminhos para a história da ciência, que ganhou uma produção mais crítica ao utilizar conceitos interdisciplinares.

Assinalemos alguns outros marcos da institucionalização da história da ciência no Brasil: criação do Núcleo de História da Ciência e da Tecnologia da Universidade de São Paulo (USP), juntamente com curso de pós-graduação e linha de pesquisa em história da ciência no Departamento de História (1973); do Centro de Lógica, Epistemologia e História, da Ciência da Universidade de Campinas (1974); do Museu de Astronomia e Ciências Afins (1985); da Casa de Oswaldo Cruz, vinculada à Fundação Oswaldo Cruz (1986); do Centro Simão Mathias de Estudos em História da Ciência, da Pontifícia Universidade Católica de São Paulo (1994), e seu curso de pós-graduação (1999); e do Grupo Interdisciplinar em Filosofia e História da Ciência, da Universidade Federal do Rio Grande do Sul (1996). 
Em 1983 surgiu a Sociedade Brasileira de História da Ciência, cujo núcleo original era da USP; a partir de 1986 tiveram início os congressos nacionais a cada dois anos. Outra evidência desse processo de crescente institucionalização da história da ciência foi o aparecimento de periódicos específicos, como Cadernos de História da Ciência e Filosofia da Ciência (1980), Revista da Sociedade Brasileira de História da Ciência (1985), Perspicullum (1987), História, Ciências, Saúde - Manguinhos (1994) e Episteme (1996).

A partir desse quadro podem ser feitas correlações com o caso específico do IBHM. A primeira diz respeito à real importância da produção veiculada pela Revista Brasileira de História da Medicina, com ampla e ininterrupta circulação durante 15 anos, a partir de 1949, portanto seis anos antes da obra que é considerada o marco inaugural da história da ciência no Brasil. Além de veicular a produção em história da medicina, a revista divulgava reuniões, solenidades, palestras realizadas pelo IBHM e/ou outros institutos da Federação, tendo como temática majoritária nomes e fatos marcantes da história da medicina no Brasil. Desse modo, a criação do Instituto Brasileiro de História da Medicina em data relativamente próxima à da Academia Brasileira de História da Ciência e a produção veiculada por seu periódico colocam-no em um patamar de pioneirismo no campo da história da ciência no Brasil.

\section{A concepção de história da medicina para Ivolino de Vasconcellos e no Instituto Brasileiro de História da Medicina}

Antes de aprofundarmos a caracterização da ciência médica pela abordagem histórica de Ivolino de Vasconcellos e do IBHM, será traçado um breve quadro da produção historiográfica da revista. Ao longo de seus 15 anos de existência, além da edição especial relativa ao biênio 1969-1970, ela publicou 103 artigos relativos à história da medicina, em sua maioria derivados de palestras e debates ocorridos nas seções mensais do Instituto, realizadas quase sempre no salão nobre da Policlínica do Rio de Janeiro.

Essa produção foi marcada por forte veia biográfica, verificável em cinqüenta dos artigos, sobressaindo, em seguida, assuntos relativos às ciências médicas em geral. Entre os biografados, predominam os brasileiros, com 33 médicos e cientistas, seguidos pelos europeus e, em menor número, profissionais da América Latina. Nota-se, também, amplo predomínio de médicos brasileiros atuantes nos séculos XIX e XX.

Com relação à autoria dos artigos da RBHM, é notável a predominância de Ivolino de Vasconcellos, que assina 53 textos, correspondentes a $52 \%$ do total publicado. A produção de Vasconcellos somada a de outros membros do IBHM chega a 77 artigos, ou $75 \%$ da produção total, o que mostra ter sido a revista principalmente 
${ }^{3}$ H. Kragh (1987) critica a primeira utilização da acepção científica do termo história, atentando para a impossibilidade da reconstrução fiel do passado, sendo a tarefa do historiador analisar, interpretar e tecer conceituações através de fontes; a concepção narrativa, simplificadoramente objetiva da história, seria, para o

historiador, mais um objeto do que um fim. um veículo do Instituto, com acentuado viés personalista. Autores não-pertencentes ao IBHM eram membros de faculdades de medicina ou associações médicas, nacionais e estrangeiras, sendo os artigos, em geral, o resultado de palestras proferidas a convite do Instituto em eventos por ele organizados.

Segundo H. Kragh (1987), autor de reflexões teóricas e epistemológicas sobre a historiografia da ciência, o termo história nos remete a duas práticas. A primeira, mais preocupada com a objetividade narrativa, ambiciona a reconstrução fidedigna do passado, ordenando cronologicamente fatos e personagens de modo a compor narrativamente um quadro fiel do passado. A segunda prática é regida por interpretação teórica mais complexa do passado e não visa apenas enumerar fatos narrativa e cronologicamente, o que a levaria a isolar-se de análises filosóficas, sociológicas e econômicas. ${ }^{3}$ Partindo dessa premissa, é possível tecer considerações sobre a concepção de história em Ivolino de Vasconcellos. Segundo suas próprias palavras,

a história é um duplo processo de narração e de interpretação. De narrar, que exige observação, minúcia, precisão e fidelidade. De interpretar, que pressupõe esse completo conhecimento objetivo e, à base dele, parte, então, para o conhecimento subjetivo, isto é, a interpretação profunda e casual, portanto, dos acontecimentos. (Vasconcellos, 1962, p.85)

Vê-se assim que Ivolino de Vasconcellos possui uma concepção de história objetiva e narrativa semelhante àquela da reconstrução fidedigna do passado abordada por Kragh. A semelhança deve-se, sobretudo, a atributos do processo narrativo para Vasconcellos, como "minúcia, precisão e fidelidade". Ele condiciona a interpretação analítica ao conhecimento objetivo: a construção da ordenação factual seria condição sine qua non para a construção do saber da história, constituindo a reflexão analítica o passo seguinte, elemento, portanto, que não guia a construção prática desse saber. Tal hierarquização revela-se ainda mais clara na passagem: "uma cabal e categorizada interpretação tem de apoiar-se na precisa e exata narrativa" (Vasconcellos, 1962, p.86).

Em suas reflexões sobre a historiografia da ciência, Kragh (1987) apresenta duas interpretações para o termo ciência: a primeira a encara como reunião de dados, conhecimentos técnicos, proposições e metodologia acabados e cientificamente aceitos, como se não houvesse um processo histórico e social por trás dessa ciência, a conformá-la. Já a segunda interpretação privilegia justamente as mentalidades e atitudes da comunidade científica durante a elaboração da metodologia e do conhecimento técnico, reconhecendo, desse modo, a existência de relações sócio-históricas a condicionar o fazer científico. 
Apesar de notar-se, nos artigos relativos à história da medicina da RBHM, certa concepção evolucionista de ciência, são privilegiados os aspectos biográficos e, por conseguinte, as relações sociais dos 'grandes nomes' da medicina. Esse caminho é seguido mediante a construção de uma imagem idealizada do biografado, englobando relações familiares, formação profissional e, muitas vezes, forte nacionalismo. A importância dada a esses aspectos acaba por realçar a faceta relativa a comportamentos, atitudes e mentalidades da ciência médica e de sua comunidade, em semelhança à segunda concepção de ciência explorada apresentada por Kragh (1987).

Para embasar tal assertiva, examinemos a biografia de Oswaldo Cruz, publicada na edição de número 2 do primeiro volume, relativa ao primeiro trimestre de 1950 (Vasconcellos, 1950, p.99). A narrativa cronológica e objetiva, onde se vê a já citada preocupação com padrões de 'precisão' e 'fidelidade', combina-se com escrita opulenta, hiperbólica, que acaba por favorecer a idealização da trajetória desse e de outros médicos biografados por Ivolino de Vasconcellos. Oswaldo Cruz é "aquele a quem o destino fundou, no Brasil, a Medicina Experimental". São descritas as origens familiares, especialmente o pai, doutor Bento Gonçalves Cruz, que faria "florir" em Oswaldo a "vocação que do berço trazia para o sublime exercício da arte médica". A caracterização dos locais de formação profissional, como a Faculdade de Medicina do Rio de Janeiro e o Instituto Pasteur de Paris, é igualmente idealizada, construindo imagens que deságuam linear e inevitavelmente na consagração do fundador da medicina experimental do Brasil. Outro aspecto é a construção de imagem nacionalista idealizada de Oswaldo Cruz, cujos estudos possuíam "um supremo objetivo... sua estremecida pátria". As doenças combatidas por ele, como a febre amarela e a peste bubônica, são descritas de tal forma que transcendem o objeto de ação e de estudo do cientista para robustecerem a imagem do salvador, imagem construída com fortes cores nacionalistas, conforme exemplifica esta passagem (p.99): "Avulta, a figura do lutador, aureolada na luz do luminoso patriotismo - avulta, e cresce, e esplende, e domina, e vence, e triunfa! Para o Brasil seria a redenção. Para Oswaldo, a glória universal. Para todos os corações brasileiros, a gratidão eterna à memória do imperecível patrício".

No entanto, permanece a questão: qual é a verdadeira função da concepção de história em Ivolino de Vasconcellos? Em já referido editorial sobre a história da medicina, ele não desconsidera a necessidade da análise subjetiva em história, apesar de priorizar o saber objetivo. Como mostra o exemplo apresentado acima, Vasconcellos não promovia análises subjetivas de seus personagens, e sim a construção de imagens idealizadas de 'heróis', fossem cientistas ou médicos. 
Em artigo de 1942, Robert Merton (1979) afirma que a utilização de avanços tecnocientíficos para fins de destruição, em guerras, desastres ambientais e práticas condenáveis à luz do ideal humanístico, levaram a uma reavaliação crítica do que deveria ser o fazer científico, a partir de pressupostos éticos. Minha hipótese é que a fundação do IBHM foi, também, impulsionada por tal autocrítica e pelo reconhecimento da necessidade de semear e fortalecer o ideal ético e humanístico do profissional de medicina, sobretudo durante sua formação. Vasconcellos (1961a, p.91) atribui a criação do Instituto Brasileiro de História da Medicina e da Federação Nacional de História da Medicina e Ciências Afins a "um ideal ético, integrando no seu programa de ação, 'as questões profissionais e de interesse moral da classe' e objetivando à 'elevação moral das profissões sanitárias'”.

Segundo Carl Schorske (2000, p.13-14), um dos modos de "pensar com a história"

Implica o emprego dos materiais do passado e das configurações em que os organizamos e compreendemos para nos orientar no presente. Em um modo, pensamos com o produto substantivo da investigação histórica, com as imagens que formamos do passado, a fim de nos definir por diferença ou semelhança a ele. Aqui, a história é um objeto para nós e nos aparece estática, uma imagem ou tableau vivant de uma cultura que pertence ao passado... implica portanto a utilização de elementos do passado na construção cultural do presente e do futuro.

Essa forma de "pensar com a história" implica, assim, a utilização do passado para ordenar as ações do presente e orientar o futuro, extraindo-se ensinamentos de episódios-chaves e dos 'grandes nomes' que deles participaram. O uso da história como 'mestra da vida', com sua concepção linear-evolucionista, remete a certa tradição iluminista e uma de suas manifestações é, justamente, o amplo emprego de biografias exemplares. Essa concepção de história assemelha-se à do Instituto Histórico e Geográfico Brasileiro (IHGB), instituto do qual Ivolino de Vasconcellos chegou a fazer parte, em seus primórdios (Guimarães, 1988), e sempre esteve muito viva no IBHM. Visava o "culto ao passado essencialmente vivo e dinâmico, buscando, nos seus feitos memoráveis e nos exemplos de suas grandes figuras, inspirações permanentes para o aperfeiçoamento e o progresso da Medicina e ciências correlatas" (RBHM, 1952, p.111). Esperava-se assim que a história da medicina desempenhasse papel essencial na missão de infundir forte elemento ético e humanista à medicina, sobretudo no que diz respeito à formação dos profissionais que a exerceriam. Nesse contexto insere-se a luta constante de Ivolino de Vasconcellos pela inclusão da cátedra de história da medicina na grade curricular da Faculdade Nacional de Medicina, da qual foi livre-docente: 
4 A Federação reunia institutos do Rio Grande do Sul, Pernambuco, Pará, Bahia, Minas Gerais, Estado do Rio, Paraíba e Paraná. A revista realizava anúncios das atividades da

Sociedade Paulista de História da Medicina, chegando Lycurgo dos Santos Filho a ser membro correspondente do IBHM. Este, através das práticas conceituadas por Hobsbawm, sempre teve uma atuação marcada pelo congraçamento institucional de instâncias científicas.

${ }^{5}$ Foram organizados congressos nacionais de história da medicina em 1951, 1953 e 1958. Neste último ano, o congresso realizou-se em conjunto com o $1^{\circ}$ Congresso Panamericano de História da Medicina. Em 1961 ocorreram o $2^{\text {o }}$ Congresso Panamericano e o 1ำ Congresso Venezuelano de História da Medicina.
A História da Medicina constitui, em verdade, uma das vigas mestras do correto aprendizado científico desta magna ciência. Parafraseando Cícero, que definiu "A História é a mestra da vida", poderemos afirmar que a História da Medicina é a Mestra das Artes Sanitárias... Qual a finalidade suprema dos estudos históricos, senão a aspiração em prol do contínuo aperfeiçoamento, e, nesse sentido, através da história das idéias e das grandes figuras que a ilustraram, pelo saber e pela ética, a consagração dos superiores modelos da deontologia médica? (Vasconcellos, 1954, p.107)

Segundo Ana Maria Alfonso-Goldfarb (1994), após a Segunda Guerra Mundial a história cresce em importância justamente por adquirir a função de humanizar a ciência e o cientista. Os indícios reunidos no presente artigo mostram que é o caso também do IBHM:

Observe-se, agora, que essa concepção basilar que possuímos da Medicina, como Ciência, Profissão e Sacerdócio, resulta de uma conceituação fundamentalmente histórica. A História está na raiz da Ciência, no âmago da profissão e na gênese do Sacerdócio. A Medicina sem História - fugindo ao próprio passado e negando, portanto, as suas origens, seria a mais fantástica e inconcebível de todas as ficções... (Vasconcellos, 1957)

\section{Sobre o Instituto Brasileiro de História da Medicina e a Federação Nacional de História da Medicina e Ciências Afins: conclusão}

Para Eric Hobsbawm (2002, p.9-23), o conceito de tradição inventada abarca um conjunto de práticas, rituais e construções históricas que servem à reação a transformações sociais. Preserva-se uma ligação com o passado a fim de estruturar de forma imutável alguns aspectos da vida social. Tais tradições revelariam aspectos intrínsecos à coesão de grupos sociais específicos ou de determinada sociedade. A história desempenharia papel central na validação desse sistema graças a seu caráter de construção, de processo seletivo e arbitrário de institucionalização e construção de identidades.

Tal como o IHGB (Guimarães, 1988), o IBHM foi fundado com o intuito de ser o instituto-sede de uma rede de congêneres ${ }^{4}$, desempenhando o papel de centralizador da produção do conhecimento. Sua existência foi marcada por aspectos que parecem confirmar o conceito de tradições inventadas proposto por Hobsbawm: práticas, rituais e construções históricas. Tendo à frente o IBHM, a Federação organizou congressos nacionais e pan-americanos ${ }^{5}$, tendo em vista sempre o potencial associativo de tal movimento. Em seus editoriais sobre esses eventos, Ivolino de Vasconcellos ressaltava sua importância para o estímulo ao campo da história da medicina, ao mesmo tempo que exaltava o pioneirismo e a importância do Instituto, sendo sua data 
6 Tal árvore encontrase localizada na ilha de Cós, e acredita-se que sob ela Hipócrates lecionou aos primeiros discípulos.

7 Proposta redigida por Ivolino de Vasconcellos em 1953 e aceita pela comunidade acadêmica da Faculdade em 1954 porém nunca concretizada, apesar dos esforços do presidente do IBHM.

${ }^{8}$ Há indicações de que, ao final de sua vida, Ivolino de Vasconcellos dedicou-se mais à advocacia, uma vez que era graduado em direito pela Faculdade de Direito do Rio de Janeiro. de fundação consagrada como o "Dia da História da Medicina". Sendo a revista explicitamente um órgão de divulgação das atividades do IBHM e de preservação de sua memória, os relatórios de atividades e editoriais que divulgam a imagem de pioneirismo e importância da instituição, recheadas de elogios e elegias de sábios estrangeiros, como Henry Sigerist, catedrático da Johns Hopkins University (RBHM, 1950), revelam um movimento arbitrário para legitimação do IBHM como principal cultor da história da medicina no Brasil, conforme os instrumentos abordados por Hobsbawm. Outra prática comum utilizada pelo IBHM, ainda na direção apontada por Hobsbawm, era a realização freqüente de palestras e visitas a monumentos de médicos ilustres, chegando Ivolino de Vasconcellos a fazer parte de uma comissão oficial para viabilizar a construção de um monumento a Oswaldo Cruz. Outro exemplo foi a mediação do IBHM no plantio de um ramo da 'Árvore de Hipócrates' ${ }^{6}$ (Vasconcellos, 1961b) no Brasil, em 1954.

No que diz respeito à atuação institucional de Ivolino de Vasconcellos, ele foi representante oficial do Brasil em inúmeros congressos internacionais, como o $4^{\circ}$ Congresso das Misericórdias, além de ser delegado oficial do Brasil na Sociedade Internacional de História da Medicina desde 1952. O IBHM possuiu em seus quadros médicos atuantes na vida pública, como Mário Pinotti e o exdeputado federal Jaeder Albergaria, o que lhe garantiu uma atuação no campo político em prol da história da medicina, a exemplo da tentativa de criação da cátedra em história da medicina na Faculdade Nacional de Medicina. ${ }^{7}$

Com o encerramento da revista, perdeu-se a fonte para contato com tal movimento associativo e seu idealizador. Sabe-se que as atividades do Instituto prosseguiram ao longo da década de 1970, porém declinando cada vez mais ao longo dos anos 80 até o falecimento de Ivolino de Vasconcellos, em 28 de janeiro de 1995 (Dicionário..., 1991). ${ }^{8}$ A Revista Brasileira de História da Medicina constitui a única fonte de estudos desse relevante movimento, relativo a uma época em que a historiografia da ciência brasileira ainda engatinhava, o que só sublinha a importância desse atuante, porém pouco abordado, médico-historiador e do movimento por ele idealizado e concretizado. 


\section{REFERÊNCIAS BIBLIOGRÁFICAS}

Alfonso-Goldfarb, Ana Maria 1994

Dicionário... 1991

Guimarães, Manoe L. Salgado 1988

Hobsbawm, Eric 2002

Kragh, Helge 1987

Merton, Robert K. 1979

RBHM 1952

RBHM 1950

Schorske, Carl 2000

Tolmasquim, A. Tiomno; Costa, A. Magno; Lino, L. Alves.

2001

Vasconcellos, Ivolino de 1962

Vasconcellos, Ivolino de 1961a

Vasconcellos, Ivolino de 1961b

Vasconcellos, Ivolino de 1957

Vasconcellos, Ivolino de 1954

Vasconcellos, Ivolino de 1950
O que é história da ciência?

São Paulo: Brasiliense.

Dicionário biobibliográfico de historiadores, geógrafos e antropólogos brasileiros. v.1 Rio de Janeiro: IHGB.

Nação e civilização nos trópicos: o Instituto Histórico e Geográfico Brasileiro e o projeto de uma história nacional. Estudos históricos, Rio de Janeiro, n.1, p.5-27.

Introdução: a invenção das tradições. In: Hobsbawm, Eric; Ranger, Terence (Org.). A invenção das tradições.

3. ed. Rio de Janeiro: Paz e Terra. p.9-23.

An introduction to the historiography of science. New York: Cambridge University Press.

Os imperativos institucionais da ciência. In: Deus, Jorge Dias de (Org.). A crítica da ciência: sociologia e ideologia da ciência. Rio de Janeiro: Jorge Zahar.

Revista Brasileira de História da Medicina.

Rio de Janeiro, v.3, n.2.

Revista Brasileira de História da Medicina. Rio de Janeiro, v.1, n.2, 1950.

Pensando com a história: indagações na passagem para o modernismo. São Paulo: Companhia das Letras.

Building the brazilian bibliography of science.

Nuncius: annali di storia della scienza, Firenze, v.16, n.2.

Editorial: História da Medicina.

Revista Brasileira de História da Medicina, Rio de Janeiro, v.13, n.3, p.85.

Biografia de 'A Oração do Médico'.

Revista Brasileira de História da Medicina, Rio de Janeiro, v.12, n.3.

Relatório sobre a Árvore de Hipócrates no Brasil. Apresentado ao XVII Congresso Internacional de História da Medicina.

Revista Brasileira de História da Medicina, Rio de Janeiro, v.12, n.3.

Editorial: impõe-se no ensino médico a Cátedra de História da Medicina. Revista Brasileira de História da Medicina, Rio de Janeiro, v.8, n.1.

Editorial: proposta a criação da Cátedra de História da Medicina na Faculdade Nacional de Medicina - a íntegra da proposição e seus signatários. Revista Brasileira de História da Medicina, Rio de Janeiro, v.5, n.1, p.107.

Galeria médica universal: Oswaldo Cruz.

Revista Brasileira de História da Medicina, Rio de Janeiro, v.1, n.2. p.99.

Recebido para publicação em agosto 2005.

Aprovado para publicação em setembro de 2006. 